\title{
Principles of Treatment for Borderline, Micropapillary Serous, and Low-Grade Ovarian Cancer
}

\author{
Kari E. Hacker, MD, PhD; Shitanshu Uppal, MBBS; and Carolyn Johnston, MD
}

\begin{abstract}
Borderline ovarian tumors (BOTs) are less common than epithelial ovarian cancers (EOCs). Low-grade EOCs (LG-EOCs) occur even less frequently than BOTs. After primary therapy, recurrence rates of BOTs and LG-EOCs are significantly lower and the stage-adjusted survival is higher than for high-grade EOCs. Thus, determining the best management in terms of traditional ovarian cancer staging and debulking procedures is more challenging and has been recently brought to question. This article reviews the particulars of BOTs and LG-EOCs, their similarities and differences, and how they are best managed and treated, and emphasizes the major role of surgery and the controversial role of chemotherapy. Because these tumors disproportionately affect younger women, this review addresses ovarian preservation in circumstances when fertility or hormonal preservation is desired.
\end{abstract}

J Natl Compr Canc Netw 2016;14(9):1175-1182

\section{NCCN: Continuing Education}

\section{Accreditation Statement}

This activity has been designed to meet the educational needs of physicians and nurses involved in the management of patients with cancer. There is no fee for this article. No commercial support was received for this article. The National Comprehensive Cancer Network (NCCN) is accredited by the ACCME to provide continuing medical education for physicians.

NCCN designates this journal-based CME activity for a maximum of 1.0 AMA PRA Category 1 Credit $^{\mathrm{TM}}$. Physicians should claim only the credit commensurate with the extent of their participation in the activity.

NCCN is accredited as a provider of continuing nursing education by the American Nurses Credentialing Center's Commission on Accreditation.

NCCN designates the education activity for a maximum of 1.0 contact hour. Accreditation as a provider refers to recognition of educational activities only; accredited status does not imply endorsement by NCCN or ANCC of any commercial products discussed/

From the Division of Gynecologic Oncology, University of Michigan, Ann Arbor, Michigan.

Submitted March 29, 2016; accepted for publication June 16, 2016. Dr. Hacker has disclosed that her spouse has stock in Celgene Corporation, AbbVie Inc., Gilead Sciences, Inc., and Halozyme Therapeutics; her spouse receives salary from Strata Oncology. The remaining authors have no financial interests, arrangements, affiliations, or commercial interests with the manufacturers of any products discussed in this article or their competitors.

Correspondence: Carolyn Johnston, MD, Division of Gynecologic Oncology, University of Michigan, 1500 East Medical Center Drive WH-L4606, Ann Arbor, MI 48109. E-mail: johnstob@med.umich.edu displayed in conjunction with the educational activity. Kristina M. Gregory, RN, MSN, OCN, is our nurse planner for this educational activity.

All clinicians completing this activity will be issued a certificate of participation. To participate in this journal CE activity: 1) review the learning objectives and author disclosures; 2 ) study the education content; 3 ) take the posttest with a $66 \%$ minimum passing score and complete the evaluation at http://education.nccn.org/ node/79469; and 4) view/print certificate.

Release date: September 1, 2016; Expiration date: September 1, 2017

\section{Learning Objectives}

Upon completion of this activity, participants will be able to:

- Describe and discuss the similarities and differences between borderline ovarian tumors (BOTs) and low-grade epithelial ovarian carcinomas (LG-EOCS)

- Assess the role of surgery, chemotherapy and fertility/ hormonal preservation in the management of BOTs and LG-EOCs

\section{EDITOR}

Kerrin M. Green, MA, Assistant Managing Editor, JNCCN-Journal of the National Comprehensive Cancer Network

Ms. Green has disclosed that she has no relevant financial relationships.

\section{CE AUTHORS}

Deborah J. Moonan, RN, BSN, Director, Continuing Education, has disclosed that she has no relevant financial relationships.

Kristina M. Gregory, RN, MSN, OCN, Vice President, Clinical Information Operations, has disclosed that she has no relevant financial relationships.

Rashmi Kumar, PhD, Senior Manager, Clinical Content, has disclosed that she has no relevant financial relationships.

Miranda Hughes, PhD, Oncology Scientist/Senior Medical Writer, has disclosed that she has no relevant financial relationships. 
The International Federation of Gynecology and Obstetrics and the WHO introduced borderline ovarian tumors (BOTs) into their classification of ovarian cancer in 1971 and 1973, respectively.,2 BOTs are 4.5 to 5.9 times less common than epithelial ovarian cancer (EOC). ${ }^{3-5}$ They constitute $10 \%$ to $20 \%$ of EOCs, and more than $95 \%$ of BOTs are of serous ( $\mathrm{sBOT}$ ) or mucinous (mBOT) histologies. BOTs have also been described less frequently in endometrioid, clear cell, and other histologies. ${ }^{5-7}$ Cancer registries in the United States stopped mandated recording of BOTs in 2001; therefore, contemporary data derives from retrospective assessments and large series in Scandinavian National Registries and Europe. BOTs usually occur in women at a mean age of 45 to 52 years, approximately 10 years younger than that of EOCs., ${ }^{5-10}$ Population-based data suggest that BOT and low-grade EOCs (LG-EOCs) are most common in white women. LG-EOC, with one-third the incidence, is more likely than BOT to occur in patients older than 45 years. ${ }^{3,11}$ Furthermore, the patient profile of low-grade serous EOC (LG-sEOC) is more comparable to that of sBOT than high-grade serous EOC (HG-sEOC). ${ }^{12}$ Three-quarters of sBOTs occur at an early stage and overall 5 -year survival is greater than 95\%,3,73-16 Their recurrence rates vary depending on stage at diagnosis, degree of surgical aggressiveness, and BOT histology, but in large contemporary series these rates range between $5 \%$ and $12 \% .{ }^{17-19}$ Among patients with BOT, $1 \%$ to $2 \%$ recur as invasive carcinomas. ${ }^{7,18,19}$ Recurrences are more common after fertility-sparing surgery. ${ }^{?}$

mBOTs are more frequently early stage than are sBOTs, with more than $90 \%$ of contemporary cases diagnosed at stage I; survival is close to $100 \%$. ${ }^{3,20}$ It is important to note that mucinous tumors of the ovary that are associated with pseudomyxoma peritonei are almost always of appendiceal origin. ${ }^{21}$ Borderline tumors displaying clear cell, endometrioid, and Brenner tumor histologies are much less common than mBOTs and sBOTs, and are usually stage I and unilateral. ${ }^{13}$ Endometrioid BOTs constitute approximately 1\% of BOTs in multiple series, and their patient demographic profile is similar to that of $\mathrm{mBOT}$ and $\mathrm{sBOT} .{ }^{22}$ Clear cell BOTs are rare with fewer than 50 cases reported in the literature. These patients are older than other patients with BOT, usually 60 to 70 years old..$^{20}$

Most risk factors for $\mathrm{sBOTs}$ are similar to those for EOC except for the use of oral contraceptives, which may not yield the same level of risk reduction; the lack of association with the protective effect of tubal ligation; familial predilection; and BRCA carrier status. ${ }^{6,8,23,24}$ Endometrioid and clear cell BOTs have been associated with estrogen excess and/or endometriosis, thus these are considered potential risk factors. ${ }^{20}$

This article reviews the spectrum from BOT (low malignant potential tumors) to low-grade carcinoma with a discussion of micropapillary features, which warrant differential consideration.

\section{Terminology and Pathology}

The most recent WHO Classification of the Tumors of the Female Genital Tract provides comprehensive diagnostic criteria, pathologic features, and associated genetic alterations in an effort to increase consistency in pathologic diagnosis of these rare tumors. ${ }^{25}$ Borderline components should comprise at least $10 \%$ of the cyst and may contain areas of invasion less than 3 to $5 \mathrm{~mm}$ in greatest linear dimension. ${ }^{26}$ Adequate sampling of the primary tumor is one section per centimeter for tumors less than $10 \mathrm{~cm}$ and 2 sections per $\mathrm{cm}$ for larger tumors. Inadequate sampling can miss an invasive cancer. ${ }^{27}$

\section{Serous Histology}

sBOTs contain epithelial cells exhibiting an unusual degree of proliferation. ${ }^{25}$ The fundamental difference between sBOTs and LG-sEOC is stromal invasion. ${ }^{26}$ If the area of invasion is small, the tumor is called an sBOT with microinvasion; these constitute $10 \%$ to $15 \%$ of sBOTs and carry a good prognosis. ${ }^{28} \mathrm{Mi}$ cropapillary serous borderline tumors (MPSCs) or noninvasive micropapillary serous carcinomas are sBOTs without invasion but with micropapillary architecture. ${ }^{28-30}$ One population-based study suggested that MPSCs constitute $26 \%$ of sBOTs, but that the micropapillary characteristic itself did not confer a worse prognosis ${ }^{31}$; this, however, remains a debated topic. Detailed gene expression analysis supports an association between MPSCs and LG-sEOC.32

Mutations in KRAS and BRAF are common in sBOTs and MPSCs, with frequencies exceeding $60 \%$, but rare in HG-EOCs. ${ }^{33,34}$ p53 mutations are more likely to occur in HG-EOC, as commonly as $95.9 \%$ of the time. ${ }^{34-38}$ The presence of KRAS and BRAF mutations and expression of $\mathrm{p} 21 / \mathrm{WAF} 1$ in LG-sEOC lends further support to their association 
with sBOT. ${ }^{34,37}$ A continuum likely exists from sBOT to LG-sEOC. The aforementioned genetic differences and histologic associations between sBOT and LG-EOC suggest that the pathogenesis of LG-EOCs and HG-EOCs is different. Wild-type p53 and activating KRAS/BRAF mutations can be useful clinically to distinguish LG-EOC and HG-EOC.

\section{Mucinous Histology}

The BOT Workshop held in Bethesda in August 2003 was instrumental in clarifying terminology for mucinous tumors, including borderline types. ${ }^{39}$ There are 2 types of histologically distinct mBOTs: gastrointestinal and endocervical or seromucinous type. mBOTs are primarily gastrointestinal type, stage I at presentation, unilateral (95\%), and rarely fatal (1\% disease-related mortality). ${ }^{39}$ Endocervicaltype $\mathrm{mBOT}$ are less common, more frequently bilateral $(30 \%-40 \%)$, confined to the ovaries, and likely to exhibit benign behavior even at higher stages..$^{39,40}$ Updated genetic assessments suggest that seromucinous BOTs do not have a serous component despite some papillary architecture, and that they are often associated with endometriosis. ${ }^{41}$

Gastrointestinal and seromucinous mBOTs are immunophenotypically distinct. ${ }^{42}$ The immunohistochemical profile of seromucinous mBOTs shows frequent expression of estrogen receptors (ERs; 100\%), progesterone receptors (PRs; 67\%), CA 125 (92\%), and CK7 (100\%). ${ }^{42}$ They do not express CDX2 or CK20, differentiating them from the gastrointestinal-type mBOTs, which express CK7 (93\%), CK20 (86\%), and CDX2 (39\%), but not ER or PR, and infrequently express CA 125 (11\%). ${ }^{42}$ These receptor patterns might be therapeutically useful.

In contrast to sBOTs, mBOTs are often associated with their invasive counterparts with mucinous carcinomas, frequently displaying areas of normal and borderline components. ${ }^{43}$ Specific gene mutations that support the progression from benign to borderline to invasive tumors are KRAS-activating mutations in exons 12 and $13 .{ }^{44}$

\section{Other Histologies}

Endometrioid BOTs display endometrioid-type epithelium with proliferative, crowded glands and nuclear atypia. ${ }^{26}$ These areas may resemble atypical endometrial hyperplasia or endometrioid carcinoma. They frequently arise in endometriotic cysts or are associated with either benign adenofibromas or endometrioid carcinomas. ${ }^{22,26} \beta$-catenin and PTEN mutations are found in endometrioid BOTs and their invasive counterparts. ${ }^{43}$ Clear cell BOTs resemble clear cell adenofibromas but display crowded glands with epithelial proliferation. ${ }^{26}$ Although an association of clear cell BOTs with invasive clear cell carcinoma exists, the gene mutation association appears to be less frequent. ${ }^{43}$ Brenner BOTs resemble transitional cell tumors of the urinary tract and display nuclear atypia and epithelial proliferation beyond that seen in a benign Brenner tumor. ${ }^{26}$ Endometrioid, clear cell, and Brenner BOTs are usually unilateral, do not have extraovarian disease or peritoneal implants, and are confined within a benign tumor of the same histology. ${ }^{20}$

\section{Micropapillary sBOTs}

Burks et $\mathrm{al}^{45}$ identified a subset of well-differentiated, noninvasive serous tumors that may be associated with malignant behavior. These are characterized by a filigree pattern of highly complex micropapillae covered by cells with a high nuclear-to-cytoplasmic ratio. ${ }^{28,45} \mathrm{~A}$ total of $75 \%$ to $92 \%$ of MPSCs are associated with sBOTs and $62 \%$ of invasive MPSCs were associated with noninvasive MPSCs, sBOTs, and/or adenofibromas, leading to the conclusion that they are related. ${ }^{45,46}$ An MPSC must have at least a 5-mm continuous length of micropapillary or cribriform ar-

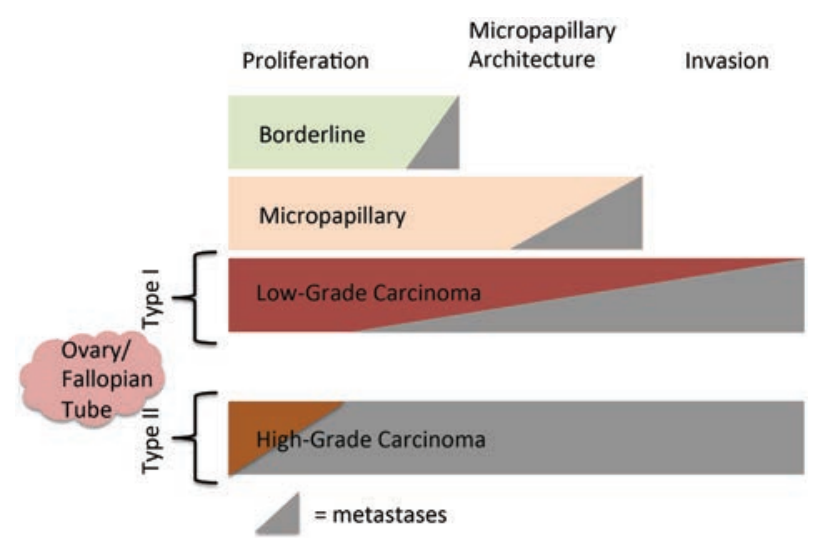

Figure 1. Serous ovarian carcinomas are divided into 2 types. All ovarian neoplasms have increased cellular proliferation. Type 2 tumors are high-grade carcinomas that typically present at advanced stage and have $p 53$ mutations. Type 1 tumors comprise low-grade carcinomas that frequently have mitogen activated protein kinase (MAPK) pathway-activating mutations. Serous borderline ovarian tumors and micropapillary serous borderline tumors commonly have MAPK-activating mutations similar to type 1 carcinomas; these tumors are not frankly invasive but may present with invasive implants. Although less common than high-grade and low-grade carcinomas, they may have metastatic implants in the peritoneal cavity. 
Hacker et al

chitecture and can display focal invasion. ${ }^{28}$ Across reviews, MPSCs are more likely than $\mathrm{SBOTs}$ to be bilateral and have surface involvement or peritoneal implants. ${ }^{28,46,47}$ In a series of MPSC from The University of Texas MD Anderson Cancer Center, Bristow et $\mathrm{al}^{48}$ reported that nearly $75 \%$ of MPSCs present at an advanced stage. Patients with MPSC confined to the ovary do well and deaths due to tumor are rare, whereas patients with advanced-stage MPSC have a disease-related mortality of $32.4 \%{ }^{48}$; of note, almost all had invasive tumor implants. Invasive implants consist of a proliferation of epithelium which effaces the underlying tissue. ${ }^{28}$ Evidence has accumulated to suggest that the poor prognosis associated with MPSCs is due to the increased presence of invasive implants. ${ }^{14,49-51}$ Typical sBOTs with invasive implants also have inferior survival. Other studies have not confirmed the association of MPSC and more frequent invasive implants, and argue that conservative surgery is a bigger factor. ${ }^{47,52}$ This apparent contradiction may be a function of sample size and of the denominator in each series, especially when it consists mostly of typically less straightforward consultative cases, thereby potentially creating an overinterpretation of the prognostic attribution of invasive implants in MPSC. ${ }^{49,52}$ Although controversy remains, we agree that both patients with sBOT and those with MPSC are more likely to do poorly if invasive implants are present, especially if they are not surgically debulked (Figure 1).

\section{Management}

\section{Borderline Tumors}

BOTs are frequently diagnosed in women of childbearing age who desire fertility preservation. In studies assessing the recurrence risk and survival of patients undergoing conservative treatment with unilateral salpingo-oophorectomy or cystectomy, ovarian preservation is consistently associated with an increased risk of recurrence but has no apparent effect on long-term survival, and most patients can be salvaged with completion surgery and debulking. ${ }^{7,17-19,53-56}$ The utility of fertility preservation has been investigated and multiple studies have cited conception rates of $40 \%$ to $60 \% .54,57,58$

Several studies have investigated the role of complete surgical staging in patients with BOTs, including peritoneal washings, peritoneal biopsies, and at least omental biopsies; many also included appendectomy and retroperitoneal lymph node sampling. ${ }^{10,17-19,53}$ They all revealed that omitting staging procedures might increase recurrence rates but does not adversely affect survival. ${ }^{10,17,18}$ Residual disease after surgery is a risk factor for recurrence, thus every effort should be made to remove all visible tumor. ${ }^{59}$ Lymph node metastases occur in sBOTs with reported incidences of $0 \%$ to $20 \%$, but are infrequent in mBOTs. ${ }^{7,53,60-62}$ Furthermore, true lymph node involvement must be distinguished from endosalpingiosis, a common benign finding of müllerian glandular inclusions. Lymph node metastases occur more commonly in patients with obvious peritoneal implants or grossly enlarged nodes at the time of surgical staging; hence it may be prudent to perform lymphadenectomy in these unique patients. ${ }^{63}$ The presence of BOT cells in retroperitoneal lymph nodes does not appear to alter prognosis,,$^{51,62,64}$ and because retroperitoneal lymph node sampling increases surgical complexity and risk, multiple groups have advocated omitting this procedure except in cases of obvious advanced disease. .4,65 $^{6}$

Minimally invasive surgery, as performed by gynecologic oncologists, is adequate treatment for BOTs. In early studies, there were more cyst ruptures with laparoscopy; however, its safety has been confirmed with no difference in rates of recurrence or survival. ${ }^{55,66}$

It is now established that conservative therapy with removal of all visible disease but without comprehensive surgical staging is an acceptable treatment for BOT. Patients may undergo unilateral salpingo-oophorectomy with preservation of the uterus and contralateral ovary for fertility preservation. For prognostic and staging reasons, it is still recommended that peritoneal and omental sampling be performed in patients without evidence of extraovarian disease; however, retroperitoneal lymph node sampling can be avoided. In patients with macroscopic disease outside of the ovary, debulking with possible lymphadenectomy is advisable, because patients with residual disease have increased rates of recurrence..$^{59,60,67}$ Recurrence rates are higher in patients who have ovarian cystectomies, thus preservation of the ipsilateral ovary is not advised except under special circumstances. ${ }^{18,19}$ Proponents of comprehensive staging argue that frozen pathology may show BOT in cases in which the final pathology reveals invasive 
carcinoma. There is credibility to these claims, with studies showing frozen pathology sensitivities of $65 \%$ to $86 \%^{53,61,68}$; however, there was no difference in survival when patients with pathology upgraded to carcinoma were included in analyses..$^{53}$ Finally, some gynecologic oncologists recommend completion of surgery after childbearing, because most recurrences are in the contralateral ovary. ${ }^{56}$

Adjuvant therapy is difficult to recommend in the treatment of BOTs because these tumors infrequently lead to death even with postoperative residual disease. ${ }^{69}$ Additionally, adjuvant chemotherapy and/or radiation therapy does not offer a survival benefit to patients with BOT., ${ }^{5,69-73}$ In some studies, patients who received adjuvant chemotherapy had worse outcomes, with lower overall survival, than those managed expectantly. ${ }^{60,69,74}$ Chemotherapy complications and secondary malignancies are valid concerns. ${ }^{27,65,73}$ For heavy disease burden or residual disease, targeted and hormonal therapies could be considered as for LG-sEOC.

When a patient has tumor recurrence, a repeat surgical procedure with complete debulking is advised because BOTs are not sensitive to chemotherapy, and because it will allow for pathologic evaluation for "malignant transformation." 67,71

\section{Micropapillary Tumors}

As with other BOTs, surgery is the mainstay of treatment for MPSCs. Stage I MPSC has a $1 \%$ to $2 \%$ recurrence risk after surgical treatment. ${ }^{14,45-47,49,50}$ Seidman and Kurman ${ }^{27}$ found that MPSCs have an 11-fold higher risk of recurrent invasive carcinoma compared with sBOTs without invasive implants. However, they recommended subsequent treatment only for those with invasive implants, noting that survival is otherwise excellent with surgery alone.

Analysis of clinical management in MPSC reveals that the amount of residual disease is the only significant factor influencing progression-free and overall survival in advanced-stage disease. ${ }^{48}$ This finding led to the conclusion that optimal surgical debulking to no visible residual disease is paramount in the management of MPSC. In a series of conservatively treated MPSCs, the biggest risk for recurrence was conservative treatment itself. ${ }^{52}$

The role for chemotherapy in the treatment of MPSC is undefined. Response rates of $75 \%$ have been cited, similar to the $57 \%$ response rate to che- motherapy in patients with sBOTs with invasive implants. ${ }^{48,60}$ Despite uncertain long-term results, many institutions still recommend chemotherapy for patients with MPSC with residual disease and for sBOTs with invasive implants or residual disease.

\section{Low-Grade Ovarian Carcinomas}

Initial Surgical Therapy: The cornerstone of management of LG-sEOC is surgical debulking. Similar to high-grade carcinoma, more than two-thirds of patients are diagnosed with stage III disease. ${ }^{75}$ Surgical debulking of LG-sEOC to no visible disease at surgery confers maximal survival benefit. In a subset analysis of LG-sEOCs from GOG 182, patients with greater than $1 \mathrm{~cm}$ and with 0.1 to $1 \mathrm{~cm}$ of residual disease had significantly higher odds of recurrence compared with patients debulked to no visible disease. ${ }^{76}$ The median progression-free survival in patients with no visible disease was 33.2 months compared with 14.7 and 14.1 months for the optimally and suboptimally debulked patients, respectively. In one of the largest retrospective analysis of patients with LG-EOC, residual disease at the completion of primary surgery was associated with a significant increased risk of dying. ${ }^{75}$ Optimal surgery includes at least hysterectomy, bilateral salpingo-oophorectomy, omentectomy, lymph node assessment, and resection of all visible disease. Optimal debulking surgery is ideally performed by a high-volume provider. ${ }^{77}$

Adjuvant and Recurrence Therapy: The role of chemotherapy in the treatment of LG-EOC is currently unclear. Data from recent studies support relative chemoresistance in LG-EOC at all phases of treatment, including in the neoadjuvant setting with a $4 \%$ complete response and an $88 \%$ stable disease rate, the adjuvant setting with a $5 \%$ negative second-look rate, and the setting of recurrent disease in which an overall response rate to various regimens is reported to be only $3.7 \% .{ }^{78-80}$

Studies quantifying the overall response rates to hormonal therapy in LG-sEOC are limited. In patients with recurrent $\mathrm{LG}$-sEOC receiving various hormonal agents, the overall response and stable disease rate are $9 \%$ and $62 \%$, respectively. ${ }^{81}$ Tumors with higher ER and PR expression appear to have better response rates. ${ }^{81}$

Acting on the knowledge that most LG-sEOCs have mutations in the MAPK pathway, a recent phase II trial found promising results, similar to those 
Hacker et al

seen with aromatase inhibitor therapy, with the use of the oral MEK1/2 inhibitor selumetinib, such that $15 \%$ and $65 \%$ of patients had an objective clinical response and stable disease, respectively. ${ }^{82}$

Several questions remain, including which subgroup, if any, benefit from adjuvant therapy. Hindered by the lack of measurable disease and overall low response rates to therapies, there is a concern that most women might have limited benefit from adjuvant therapy while having to endure the side effects of treatment .

\section{Conclusions}

BOTs, MPSCs, and LG-sEOCs are a less common group of ovarian tumors with distinctly different epidemiology and biologic behavior than HG-EOC. They display an indolent presentation and recurrence pattern, making them challenging to study. Furthermore, studies have generally consisted of variably staged and treated patients, causing a consensus statement on the best treatment to be challenging to substantiate. We agree with the Gynecologic Cancer InterGroup guidelines that BOTs should be treated exclusively with surgery and LG-sEOCs should be debulked with consideration of hormonal or targeted molecular therapies for residual or recurrent disease. ${ }^{83,84}$ Attempts to treat these patients identically to those with HG-EOCs should cease outside of the role for surgical debulking. Other support for differential management comes from mutational analyses that suggest sBOTs and LG-EOC are related, whereas HG-EOCs are a separate entity. ${ }^{29}$ Clinical trials examining the use of novel agents and hormonal therapy need to be conducted with an observational control arm. We also need better clarification of which histologic and immunologic factors, if any, identify truly high-risk patients who may benefit from more aggressive staging, adjuvant therapy, or closer surveillance.

\section{References}

1. Classification and staging of malignant tumours in the female pelvis. Acta Obstet Gynecol Scand 1971;50:1-7.

2. Serov SF, Scully RE, Sobin LH. Histological Typing of Ovarian Tumors. International Histologic Classification of Tumours, No. 9. Geneva, Switzerland: World Health Organization; 1973.

3. Morris CR, Liu L, Rodriguez AO, et al. Epidemiologic features of borderline ovarian tumors in California: a population-based study. Cancer Causes Control 2013;24:665-674.
4. Skírnisdóttir I, Garmo H, Wilander E, Holmberg L. Borderline ovarian tumors in Sweden 1960-2005: trends in incidence and age at diagnosis compared to ovarian cancer. Int J Cancer 2008;123:1897-1901.

5. Auranen A, Grénman S, Mäkinen J, et al. Borderline ovarian tumors in Finland: epidemiology and familial occurrence. Am J Epidemiol 1996;144:548-553.

6. Madsen C, Baandrup L, Dehlendorff C, Kjaer SK. Tubal ligation and salpingectomy and the risk of epithelial ovarian cancer and borderline ovarian tumors: a nationwide case-control study. Acta Obstet Gynecol Scand 2015;94:86-94.

7. Zanetta G, Rota S, Chiari S, et al. Behavior of borderline tumors with particular interest to persistence, recurrence, and progression to invasive carcinoma: a prospective study. J Clin Oncol 2001;19:2658-2664.

8. Modugno F, Ness RB, Wheeler JE. Reproductive risk factors for epithelial ovarian cancer according to histologic type and invasiveness. Ann Epidemiol 2001;11:568-574

9. Harris R, Whittemore AS, Itnyre J. Characteristics relating to ovarian cancer risk: collaborative analysis of 12 US case-control studies. III Epithelial tumors of low malignant potential in white women. Collaborative Ovarian Cancer Group. Am J Epidemiol 1992;136:1204-1211.

10. Trillsch F, Mahner S, Vettorazzi E, et al. Surgical staging and prognosis in serous borderline ovarian tumours (BOT): a subanalysis of the AGO ROBOT study. Br J Cancer 2015;112:660-666.

11. Mink PJ, Sherman ME, Devesa SS. Incidence patterns of invasive and borderline ovarian tumors among white women and black women in the United States. Results from the SEER Program, 1978-1998. Cancer 2002;95:2380-2389.

12. Plaxe SC. Epidemiology of low-grade serous ovarian cancer. Am J Obstet Gynecol 2008;198:459.e1-8; discussion 459.e8-9.

13. Gershenson DM. Clinical management potential tumours of low malignancy. Best Pract Res Clin Obstet Gynaecol 2002;16:513-527.

14. Longacre TA, McKenney JK, Tazelaar HD, et al. Ovarian serous tumors of low malignant potential (borderline tumors): outcome-based study of 276 patients with long-term ( $>$ or $=5$-year) follow-up. Am J Surg Pathol 2005;29:707-723.

15. Sherman ME, Mink PJ, Curtis R, et al. Survival among women with borderline ovarian tumors and ovarian carcinoma. Cancer 2004;100:10451052.

16. Trimble CL, Kosary C, Trimble EL. Long-term survival and patterns of care in women with ovarian tumors of low malignant potential. Gynecol Oncol 2002;86:34-37.

17. Guvenal T, Dursun P, Hasdemir PS, et al. Effect of surgical staging on 539 patients with borderline ovarian tumors: a Turkish Gynecologic Oncology Group study. Gynecol Oncol 2013;131:546-550.

18. du Bois A, Ewald-Riegler N, de Gregorio N, et al. Borderline tumours of the ovary: a cohort study of the Arbeitsgmeinschaft Gynäkologische Onkologie (AGO) Study Group. Eur J Cancer 2013;49:1905-1914.

19. Suh-Burgmann E. Long-term outcomes following conservative surgery for borderline tumor of the ovary: a large population-based study. Gynecol Oncol 2006;103:841-847.

20. Seidman JD, Cho KR, Ronnett BM, Kurman RJ. Surface epithelial tumors of the ovary. In: Kurman RJ, Ronnett BM, eds. Blaustein's Pathology of the Female Genital Tract. New York, NY: Springer US; 2011:679-784.

21. Seidman JD, Ronnett BM, Kurman RJ. Pathology of borderline (low malignant potential) ovarian tumours. Best Pract Res Clin Obstet Gynaecol 2002;16:499-512.

22. Bell KA, Kurman RJ. A clinicopathologic analysis of atypical proliferative (borderline) tumors and well-differentiated endometrioid adenocarcinomas of the ovary. Am J Surg Pathol 2000;24:1465-1479.

23. Shushan A, Paltiel O, Gordon L, Schenker JG. Ovarian cancer of low malignant potential is not associated with positive familial history. Am J Obstet Gynecol 1996;175:507-508.

24. Gotlieb WH, Chetrit A, Menczer J, et al. Demographic and genetic characteristics of patients with borderline ovarian tumors as compared to early stage invasive ovarian cancer. Gynecol Oncol 2005;97:780-783.

25. Kurman RJ. WHO Classification of Tumours of Female Reproductive Organs. Lyons, France: IARC Press; 2014.

26. Seidman JD, Soslow RA, Vang R, et al. Borderline ovarian tumors: diverse contemporary viewpoints on terminology and diagnostic criteria with illustrative images. Hum Pathol 2004;35:918-933.

27. Seidman JD, Kurman RJ. Subclassification of serous borderline tumors of the ovary into benign and malignant types. A clinicopathologic study of 65 advanced stage cases. Am J Surg Pathol 1996;20:1331-1345. 
28. Bell DA, Longacre TA, Prat J, et al. Serous borderline (low malignant potential, atypical proliferative) ovarian tumors: workshop perspectives. Hum Pathol 2004;35:934-948.

29. Schüler S, Ponnath M, Engel J, Ortmann O. Ovarian epithelial tumors and reproductive factors: a systematic review. Arch Gynecol Obstet 2013;287:1187-1204

30. Kurman RJ, Shih IM. Pathogenesis of ovarian cancer: lessons from morphology and molecular biology and their clinical implications. Int J Gynecol Pathol 2008;27:151-160.

31. Gilks CB, Alkushi A, Yue JJ, et al. Advanced-stage serous borderline tumors of the ovary: a clinicopathological study of 49 cases. Int J Gynecol Pathol 2003;22:29-36.

32. May T, Virtanen C, Sharma M, et al. Low malignant potential tumor with micropapillary features are molecularly similar to low-grade serous carcinoma of the ovary. Gynecol Oncol 2010;117:9-17.

33. Sieben NL, Macropoulos P, Roemen GM, et al. In ovarian neoplasms, BRAF, but not KRAS, mutations are restricted to low-grade serous tumours. J Pathol 2004;202:336-340.

34. Singer G, Oldt R III, Cohen Y, et al. Mutations in BRAF and KRAS characterize the development of low-grade ovarian serous carcinoma. J Natl Cancer Inst 2003;95:484-486.

35. Caduff RF, Svoboda-Newman SM, Ferguson AW, et al. Comparison of mutations of Ki-RAS and p53 immunoreactivity in borderline and malignant epithelial ovarian tumors. Am J Surg Pathol 1999;23:323-328.

36. Hutson R, Ramsdale J, Wells M.p53 protein expression in putative precursor lesions of epithelial ovarian cancer. Histopathology 1995;27:367-371.

37. Meinhold-Heerlein I, Bauerschlag D, Hilpert F, et al. Molecular and prognostic distinction between serous ovarian carcinomas of varying grade and malignant potential. Oncogene 2005;24:1053-1065.

38. Cancer Genome Atlas Research Network. Integrated genomic analyses of ovarian carcinoma. Nature 2011;474:609-615.

39. Ronnett BM, Kajdacsy-Balla A, Gilks CB, et al. Mucinous borderline ovarian tumors: points of general agreement and persistent controversies regarding nomenclature, diagnostic criteria, and behavior. Hum Pathol 2004;35:949-960

40. Shappell HW, Riopel MA, Smith Sehdev AE, et al. Diagnostic criteria and behavior of ovarian seromucinous (endocervical-type mucinous and mixed cell-type) tumors: atypical proliferative (borderline) tumors, intraepithelial, microinvasive, and invasive carcinomas. Am J Surg Pathol 2002;26:1529-1541.

41. Kurman RJ, Shih IM. Seromucinous tumors of the ovary. What's in a name? Int J Gynecol Pathol 2016;35:78-81.

42. Vang R, Gown AM, Barry TS, et al. Ovarian atypical proliferative (borderline) mucinous tumors: gastrointestinal and seromucinous (endocervical-like) types are immunophenotypically distinctive. Int Gynecol Pathol 2006;25:83-89.

43. Shih IM, Kurman RJ. Molecular pathogenesis of ovarian borderline tumors: new insights and old challenges. Clin Cancer Res 2005;11:7273-7279.

44. Mok SC, Bell DA, Knapp RC, et al. Mutation of K-ras protooncogene in human ovarian epithelial tumors of borderline malignancy. Cancer Res 1993;53:1489-1492.

45. Burks RT, Sherman ME, Kurman RJ. Micropapillary serous carcinoma of the ovary. A distinctive low-grade carcinoma related to serous borderline tumors. Am J Surg Pathol 1996;20:1319-1330.

46. Smith Sehdev AE, Sehdev PS, Kurman RJ. Noninvasive and invasive micropapillary (low-grade) serous carcinoma of the ovary: a clinicopathologic analysis of 135 cases. Am J Surg Pathol 2003;27:725736.

47. Slomovitz BM, Caputo TA, Gretz HF III, et al. A comparative analysis of 57 serous borderline tumors with and without a noninvasive micropapillary component. Am J Surg Pathol 2002;26:592-600.

48. Bristow RE, Gossett DR, Shook DR, et al. Micropapillary serous ovarian carcinoma: surgical management and clinical outcome. Gynecol Oncol 2002;86:163-170

49. Prat J, De Nictolis M. Serous borderline tumors of the ovary: a long-term follow-up study of 137 cases, including 18 with a micropapillary pattern and 20 with microinvasion. Am J Surg Pathol 2002;26:1111-1128.

50. Chang SJ, Ryu HS, Chang KH, et al. Prognostic significance of the micropapillary pattern in patients with serous borderline ovarian tumors. Acta Obstet Gynecol Scand 2008;87:476-481.

51. Seidman JD, Kurman RJ. Ovarian serous borderline tumors: a critical review of the literature with emphasis on prognostic indicators. Hum Pathol 2000;31:539-557.
52. Uzan C, Kane A, Rey A, et al. Prognosis and prognostic factors of the micropapillary pattern in patients treated for stage II and III serous borderline tumors of the ovary. Oncologist 2011;16:189-196.

53. Winter WE III, Kucera PR, Rodgers W, et al. Surgical staging in patients with ovarian tumors of low malignant potential. Obstet Gynecol 2002;100:671-676

54. Boran N, Cil AP, Tulunay G, et al. Fertility and recurrence results of conservative surgery for borderline ovarian tumors. Gynecol Oncol 2005;97:845-851.

55. Ren J, Peng Z, Yang K. A clinicopathologic multivariate analysis affecting recurrence of borderline ovarian tumors. Gynecol Oncol 2008;110:162167.

56. Uzan C, Muller E, Kane A, et al. Prognostic factors for recurrence after conservative treatment in a series of 119 patients with stage I serous borderline tumors of the ovary. Ann Oncol 2014;25:166-171.

57. Morris RT, Gershenson DM, Silva EG, et al. Outcome and reproductive function after conservative surgery for borderline ovarian tumors. Obstet Gynecol 2000;95:541-547.

58. Gotlieb WH, Flikker S, Davidson B, et al Borderline tumors of the ovary: fertility treatment, conservative management, and pregnancy outcome. Cancer 1998;82:141-146.

59. Leake JF, Currie JL, Rosenshein NB, Woodruff JD. Long-term followup of serous ovarian tumors of low malignant potential. Gynecol Oncol 1992;47:150-158.

60. Gershenson DM, Silva EG, Levy L, et al. Ovarian serous borderline tumors with invasive peritoneal implants. Cancer 1998;82:1096-1103.

61. Lin PS, Gershenson DM, Bevers MW, et al. The current status of surgical staging of ovarian serous borderline tumors. Cancer 1999;85:905-911.

62. Leake JF, Rader JS, Woodruff JD, Rosenshein NB. Retroperitoneal lymphatic involvement with epithelial ovarian tumors of low malignant potential. Gynecol Oncol 1991;42:124-130.

63. Camatte S, Morice P, Atallah D, et al. Lymph node disorders and prognostic value of nodal involvement in patients treated for a borderline ovarian tumor: an analysis of a series of 42 lymphadenectomies. J Am Coll Surg 2002;195:332-338.

64. Kanat-Pektas $M$, Ozat $M$, Gungor $T$, et al. Complete lymph node dissection: is it essential for the treatment of borderline epithelial ovarian tumors? Arch Gynecol Obstet 2011;283:879-884.

65. Kurman RJ, Trimble CL. The behavior of serous tumors of low malignant potential: are they ever malignant? Int J Gynecol Pathol 1993;12:120-127.

66. Desfeux P, Camatte S, Chatellier G, et al. Impact of surgical approach on the management of macroscopic early ovarian borderline tumors. Gynecol Oncol 2005;98:390-395.

67. Bostwick DG, Tazelaar HD, Ballon SC, et al. Ovarian epithelial tumors of borderline malignancy. A clinical and pathologic study of 109 cases. Cancer 1986;58:2052-2065.

68. Shih KK, Garg K, Soslow RA, et al. Accuracy of frozen section diagnosis of ovarian borderline tumor. Gynecol Oncol 2011;123:517-521.

69. Chambers JT, Merino MJ, Kohorn EI, Schwartz PE. Borderline ovarian tumors. Am J Obstet Gynecol 1988;159:1088-1094.

70. Creasman WT, Park R, Norris H, et al. Stage I borderline ovarian tumors. Obstet Gynecol 1982;59:93-96.

71. Crispens MA, Bodurka D, Deavers M, et al. Response and survival in patients with progressive or recurrent serous ovarian tumors of low malignant potential. Obstet Gynecol 2002;99:3-10.

72. Sutton GP, Bundy BN, Omura GA, et al. Stage III ovarian tumors of low malignant potential treated with cisplatin combination therapy (a Gynecologic Oncology Group study). Gynecol Oncol 1991;41:230-233.

73. Tropé C, Kaern J, Vergote IB, et al. Are borderline tumors of the ovary overtreated both surgically and systemically? A review of four prospective randomized trials including 253 patients with borderline tumors. Gynecol Oncol 1993;51:236-243.

74. Shih KK, Zhou QC, Aghajanian C, et al. Patterns of recurrence and role of adjuvant chemotherapy in stage II-IV serous ovarian borderline tumors. Gynecol Oncol 2010;119:270-273.

75. Gershenson DM, Bodurka DC, Lu KH, et al. Impact of age and primary disease site on outcome in women with low-grade serous carcinoma of the ovary or peritoneum: results of a large single-institution registry of a rare tumor. J Clin Oncol 2015;33:2675-2682.

76. Fader AN, Java J, Ueda S, et al. Survival in women with grade 1 serous ovarian carcinoma. Obstet Gynecol 2013;122(2 Pt 1):225-232. 
77. Cowan RA, O'Cearbhaill RE, Gardner GJ, et al. Is it time to centralize ovarian cancer care in the United States? Ann Surg Oncol 2016;23:989_ 993.

78. Schmeler KM, Sun CC, Bodurka DC, et al. Neoadjuvant chemotherapy for low-grade serous carcinoma of the ovary or peritoneum. Gynecol Oncol 2008;108:510-514.

79. Gershenson DM, Sun CC, Lu KH, et al. Clinical behavior of stage II-IV low-grade serous carcinoma of the ovary. Obstet Gynecol 2006;108:361368.

80. Gershenson DM, Sun CC, Bodurka D, et al. Recurrent low-grade serous ovarian carcinoma is relatively chemoresistant. Gynecol Oncol $2009 ; 114: 48-52$
81. Gershenson DM, Sun CC, Iyer RB, et al. Hormonal therapy for recurrent low-grade serous carcinoma of the ovary or peritoneum. Gynecol Oncol 2012;125:661-666

82. Farley J, Brady WE, Vathipadiekal V, et al. Selumetinib in women with recurrent low-grade serous carcinoma of the ovary or peritoneum: an openlabel, single-arm, phase 2 study. Lancet Oncol 2013;14:134-140.

83. Harter P, Gershenson D, Lhomme C, et al. Gynecologic Cancer InterGroup (GCIG) consensus review for ovarian tumors of low malignant potential (borderline ovarian tumors). Int J Gynecol Cancer 2014;24(9 Suppl 3):S5-8.

84. Gourley C, Farley J, Provencher DM, et al. Gynecologic Cancer InterGroup (GCIG) consensus review for ovarian and primary peritoneal low-grade serous carcinomas. Int J Gynecol Cancer 2014;24(9 Suppl 3):S9-13.

\section{Instructions for Completion}

To participate in this journal CE activity: 1) review the learning objectives and author disclosures; 2 ) study the education content; 3 ) take the posttest with a $66 \%$ minimum passing score and complete the evaluation at http://education.nccn.org/ node/79469; and 4) view/print certificate. After reading the article, you should be able to answer the following multiple- choice questions. Credit cannot be obtained for tests completed on paper. You must be a registered user on NCCN.org. If you are not registered on NCCN.org, click on "New Member? Sign up here" link on the left hand side of the Web site to register. Only one answer is correct for each question. Once you successfully answer all posttest questions you will be able to view and/or print your certificate. Software requirements: Internet

\section{Posttest Questions}

1. Which of following statements regarding BOTs and LG-EOCs are true?

a. The fundamental difference between sBOTs and SLG-EOC is stromal invasion

b. MPSCs are sBOTs without invasion but with micropapillary architecture

c. Detailed gene expression analysis supports an association between MPSCs and LG-sEOCs

d. All of the above

2. Which of the following statements regarding BOTs is FALSE?

a. BOTs are frequently diagnosed in women of childbearing age who desire fertility preservation b. Residual disease after surgery is a risk factor for recurrence thus every effort should be made to remove all visible tumor

c. Adjuvant therapy is no longer recommended because these tumors infrequently lead to death even with postoperative residual disease

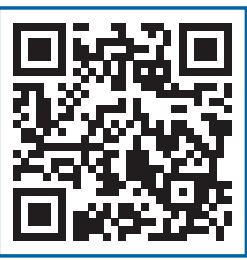

d. Repeat surgery with complete debulking is not advised in the case of tumor recurrence

3. True or False: The utility of fertility preservation in patients with BOTs has been investigated and multiple studies have cited conception rates of $40 \%$ to $60 \%$. 